\title{
A viewpoint on catalytic origin of boron nitride in oxidative dehydrogenation of light alkanes
}

\author{
Lei Shi a, Dongqi Wang b, An-Hui Lu a,* \\ a State Key Laboratory of Fine Chemicals, School of Chemical Engineering, Dalian University of Technology, Dalian 116024, Liaoning, China \\ b Center for Multi-disciplinary Research, Institute of High Energy Physics, Chinese Academy of Sciences, Beijing 100049, China
}

\section{A R T I C L E I N F O}

\section{Article history:}

Received 26 January 2018

Accepted 22 February 2018

Published 5 May 2018

\section{Keywords:}

Boron nitride

Zig-zag edge

$\mathrm{B}-\mathrm{OH}$ group

Light alkanes

Oxidative dehydrogenation

Induction period

\begin{abstract}
A B S T R A C T
Oxidative dehydrogenation of light alkanes to alkenes is an attractive alternative route for industrial direct dehydrogenation because of favorable thermodynamic and kinetic characteristics, but encounters difficulties in selectivity control for alkenes because of over-oxidation reactions that produce a substantial amount of undesired carbon oxides. Recent progress has revealed that boron nitride is a highly promising catalyst in the oxidative dehydrogenation of light alkanes because of its superior selectivity for and high productivity of light alkenes, negligible formation of $\mathrm{CO}_{2}$, and remarkable catalyst stability. From this viewpoint, recent works on boron nitride in the oxidative dehydrogenations of ethane, propane, butane, and ethylbenzene are reviewed, and the emphasis of this viewpoint is placed on discussing the catalytic origin of boron nitride in oxidative dehydrogenation reactions. After analyzing recent progress in the use of boron nitride for oxidative dehydrogenation reactions and finding much new evidence, we conclude that pure boron nitride is catalytically inert, and an activation period is required under the reaction conditions; this process is accompanied by an oxygen functionalization at the edge of boron nitride; the B-O species themselves have no catalytic activity in $\mathrm{C}-\mathrm{H}$ cleavage, and the $\mathrm{B}-\mathrm{OH}$ groups, with the assistance of molecular oxygen, play the key role in triggering the oxidative dehydrogenation of propane; the dissociative adsorption of molecular oxygen is involved in the reaction process; and a straightforward strategy for preparing an active boron nitride catalyst with hydroxyl groups at the edges can efficiently enhance the catalytic efficacy. A new redox reaction cycle based on the $\mathrm{B}-\mathrm{OH}$ sites is also proposed. Furthermore, as this is a novel catalytic system, there is an urgent need to develop new methods to optimize the catalytic performances, clarify the catalytic function of boron species in the alkane ODH reactions, and disclose the reaction mechanism under realistic reaction conditions.
\end{abstract}

(C) 2018, Dalian Institute of Chemical Physics, Chinese Academy of Sciences. Published by Elsevier B.V. All rights reserved.

\section{Introduction}

Light olefins $\left(\mathrm{C}_{2}=-\mathrm{C}_{4}=\right)$ are the most important feedstocks in the chemical industry, with a global production of $>200$ million metric tons per year, and are currently produced through ei- ther the cracking of petroleum-derived hydrocarbons or a multistage coal-based methanol-to-olefins process that commonly involves extensive energy consumption and results in enormous carbon emissions [1-3].

The recent increase in the availability of worldwide shale

\footnotetext{
*Corresponding author. Tel/Fax: (0411)84986112; E-mail: anhuilu@dlut.edu.cn

This work was supported by State Key Program of the National Natural Science Foundation of China (21733002), the National Natural Science Foundation of China (U1462120, 21403027), and Cheung Kong Scholars Programme of China (T2015036).

DOI: 10.1016/S1872-2067(18)63060-8 | http://www.sciencedirect.com/science/journal/18722067 | Chin. J. Catal., Vol. 39, No. 5, May 2018
} 
gas and natural gas resources, which contain considerable amounts of light alkanes $\left(\mathrm{C}_{2}-\mathrm{C}_{4}\right)$, has stimulated a quick technical shift to obtaining commodity light olefins through gas-based dehydrogenation routes [4,5]. Taking propylene production as an example, catalytic dehydrogenation of propane (PDH) has supplied $\sim 5 \%$ of global propylene, and this is anticipated to increase to $20 \%$ by 2020 [6]. Nevertheless, direct dehydrogenation protocols relying on platinum- or chromium oxide-based catalysts practically suffer from thermodynamic limitations in further enhancing the reaction efficiency and also rapid catalyst deactivation through coking and catalyst sintering, and thus require frequent regeneration of the catalysts under harsh conditions $[7,8]$.

Oxidative dehydrogenation $(\mathrm{ODH})$ is an attractive alternative to direct dehydrogenation processes because of favorable thermodynamic and kinetic characteristics, e.g., exothermic, lower reaction temperature, faster reaction rate, and especially no coking [9-11]. In the past few decades, catalytic systems giving good performances in the ODH reaction of light alkanes have been those based on transition metal oxides (e.g., $\mathrm{V}_{2} \mathrm{O}_{5}$, $\mathrm{MoO}_{3}$, and $\mathrm{NiO}$ ) or alkaline-earth metal oxychlorides [12]. However, the formed electron-rich olefins easily react with the surfaces of metal oxide catalysts, resulting in the cleavage of the $\mathrm{C}-\mathrm{C}$ bond through a subsequent oxygen insertion, thus forming the undesired over-oxidation product, $\mathrm{CO}_{2}$. As summarized in Fig. 1(A) for the well-developed metal oxide catalysts, the over-oxidation product, $\mathrm{CO}_{2}$, constitutes a very high proportion of the products, typically around $20 \%$ and in some cases even $50 \%$, at conversion levels of $\sim 20 \%$, a typical value of industrial interest [13-22]. There is therefore an urgent need to develop new catalysts that can produce olefins with high selectivity under the severe conditions of alkane activation, but this is a great challenge.

\section{Boron nitride, an active catalyst for $\mathrm{ODH}$ reactions}

Boron nitride has been extensively applied in the fields of physics, electronics, and aerospace as a sealing material, taking advantage of its excellent anti-oxidation properties and structural stability $[23,24]$. In catalysis research, boron nitride is generally considered to be chemically inert, and has been used merely as a carrier for a long time [25,26]. Also, Fu and Bao $[27,28]$ have confirmed that a boron nitride cover can be used as a promoter to tune molecule-metal interactions and enhance metal-catalyzed reactions. Recently, the Hermans group at University of Wisconsin-Madison, USA, and our research group at Dalian University of Technology, China, independently disclosed that boron nitride could efficiently catalyze the oxidative dehydrogenation of propane to propylene with impressive selectivity, and with only negligible $\mathrm{CO}_{2}$ formation (Fig. 1(A)) $[29,30]$. It is important to highlight that such a novel catalyst system addresses the difficulty of selectivity control for olefins that has long existed in oxidative dehydrogenation because of the over-oxidation reactions that produce a substantial amount of undesired $\mathrm{CO}_{2}$.

In Hermans' study, hexagonal boron nitride ( $h$-BN) exhibited high selectivity for propylene (79\%) and ethylene (12\%) at a $14 \%$ conversion level of propane [29]. In our case, edge-hydroxylation treatment granted boron nitride higher activity (20.6\%), selectivity (80.2\%), and stability for at least $300 \mathrm{~h}$ [30]. Our control experiment with a feed gas of propylene and molecular oxygen also showed that the boron nitride catalyst has almost no activity for propylene oxidation, and thus prevents its over-oxidation to $\mathrm{CO}_{2}$ [30]. One of the most important requirements for commercially attractive oxidative dehydrogenation catalysts is high productivity (golefin $\mathrm{g}_{\mathrm{cat}^{-1}} \mathrm{~h}^{-1}$ ) of the olefins. Hexagonal boron nitride exhibited a productivity of $\sim 1$ golefin gcat $^{-1} \mathrm{~h}^{-1}$ [29], while hydroxylated boron nitride (BNOH) showed a higher olefin production of $6.8 \mathrm{golefin}_{\text {cat }} \mathrm{g}^{-1} \mathrm{~h}^{-1}$ (Fig. 1(B)), which is far higher than those of metal oxide catalysts.

In addition to the ODH reaction of propane, follow-up reports showed that boron nitrides were active catalysts for the oxidative dehydrogenations of $n$-butane and isobutane [32] and ethane [33], with the latter conducted at higher temperatures. The study on ethane ODH also demonstrated the outstanding high-temperature oxidation resistance of boron nitride. For example, using a hydroxylated boron nitride catalyst, at a very high conversion level of $63 \%$, the ethylene selectivity was $80 \%$, which is comparable to that of the industrial steam-cracking route [33]. All of these results confirmed that boron nitride offers rather high selectivity, and only small amounts of $\mathrm{CO}_{2}$ are
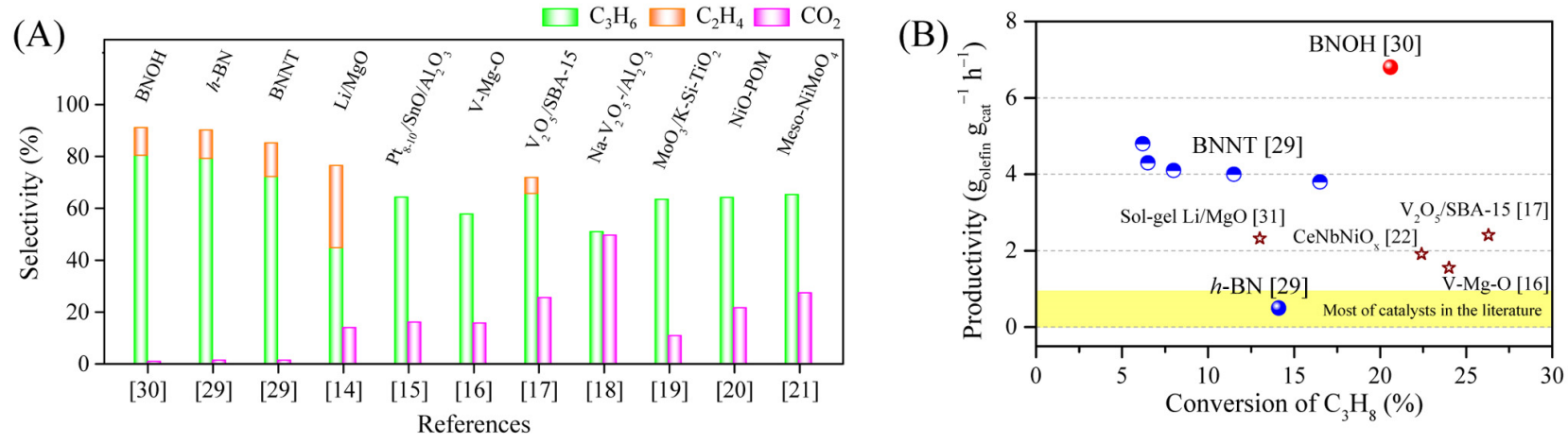

Fig. 1. (A) Comparison of selectivities toward light olefins and $\mathrm{CO}_{2}$ in propane $\mathrm{ODH}$ at $\sim 20 \%$ conversion for several representative catalysts; (B) Comparison of productivities for olefins of several boron-nitride-based catalysts with those of reported catalysts. Data from Refs. [14-31]. 
formed. A recent report showed that boron nitride nanosheets have delivered a remarkable $60 \%$ selectivity at an ethane conversion of $78 \%$ and remained stable over $400 \mathrm{~h}$ [34]. In addition, carbon-doped boron nitride nanosheets have also shown high activity and selectivity in the oxidative dehydrogenation of ethylbenzene to styrene, as well as excellent oxidation resistance [35].

\section{The catalytic origin of boron nitride in the $\mathrm{ODH}$ reaction}

Although these studies corroborate the unprecedented catalytic properties of boron nitride in the oxidative dehydrogenation of light alkanes, the origin of the catalytic behavior of such a novel and unique catalyst system is still controversial. This is actually normal for the emergence of new catalysts. Based on DFT calculations, Hermans and coworkers [29] proposed that the B-O-O-N intermediate formed on an armchair edge of boron nitride by activating molecular oxygen was likely to be the catalytically active site for the cleavage of the initial $\mathrm{C}-\mathrm{H}$ bond in propane (Fig. 2(A)). However, many studies have shown that the most frequently exposed terminals in hexagonal boron nitride materials are zig-zag edges [36-38]. It appears that the deduction based on the armchair edge and the B-O-O-N intermediate remains to be clarified.

In our earliest investigation, both hexagonal boron nitride and boron nitride nanotubes (BNNTs) were tested in the oxida-
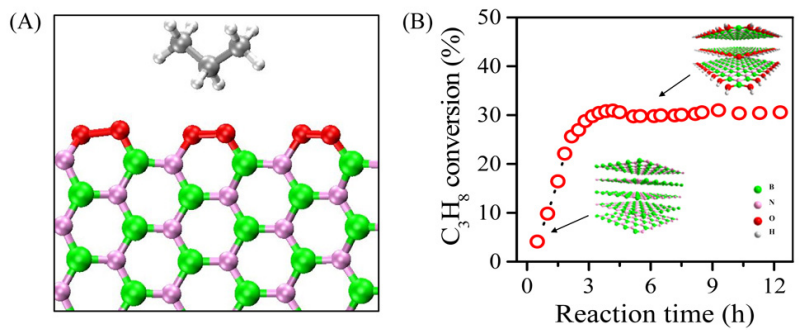

Fig. 2. (A) Proposed radical rebound mechanism for hydrogen atom abstraction from propane to oxygen-terminated armchair boron nitride edge site in Hermans' paper [29]. Green represents boron, pink represents nitrogen, red represents oxygen, dark grey represents carbon, and light grey represents hydrogen. (B) Propane conversion as a function of reaction time in propane $\mathrm{ODH}$ over pristine $h$-BN. Reaction conditions: $530{ }^{\circ} \mathrm{C}$, catalyst weight $100 \mathrm{mg}$, gas feed $16.7 \mathrm{vol} \% \mathrm{C}_{3} \mathrm{H}_{8}, 25.1$ vol. $\% \mathrm{O}_{2}$, and He balance, space velocity $9.4 \mathrm{~g}_{\mathrm{C} 3 \mathrm{H} 8} \mathrm{~g}_{\mathrm{cat}}{ }^{-1} \mathrm{~h}^{-1}$.

tive dehydrogenation reaction of propane. It appeared that these two materials exhibited very low initial activity (typically $<3 \%$ ) for propane conversion, and there existed a catalyst activation period, i.e., a gradual increase in propane conversion along with the ODH reaction progress (Fig. 2(B)). This suggests that it is difficult for the intact boron nitride to activate molecular oxygen under the ODH reaction conditions. The catalytic activity most likely originates from the in situ surface functionalization of boron nitride under the reaction conditions. Thus, there is a compelling need to rationally tailor terminated edges
(A)

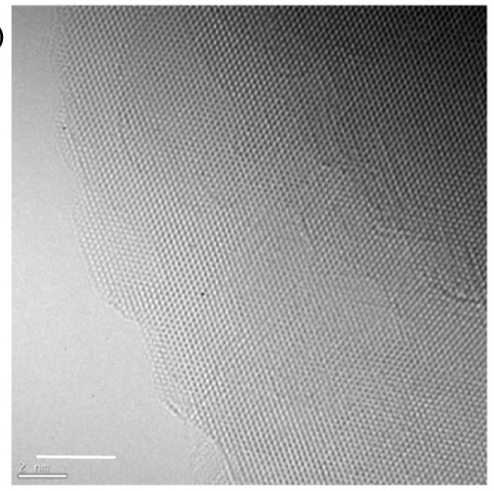

(D)

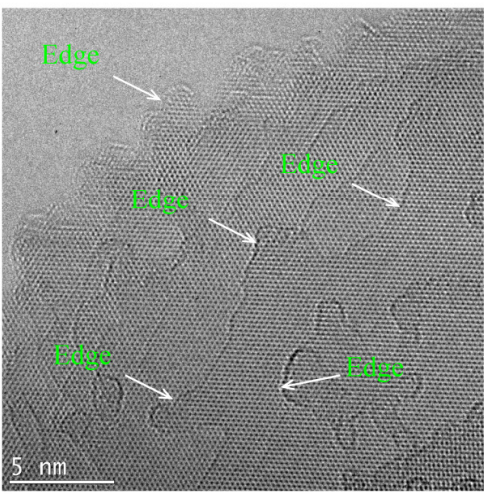

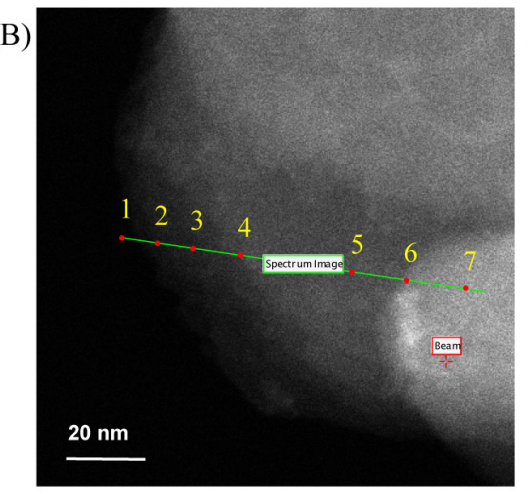

(E)

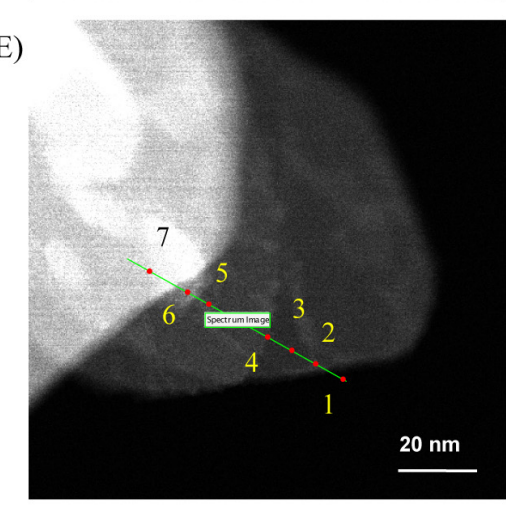

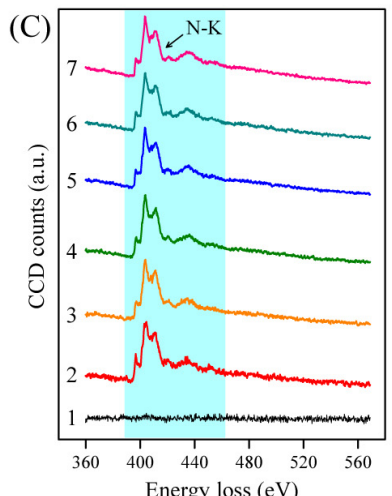

Energy loss (eV)

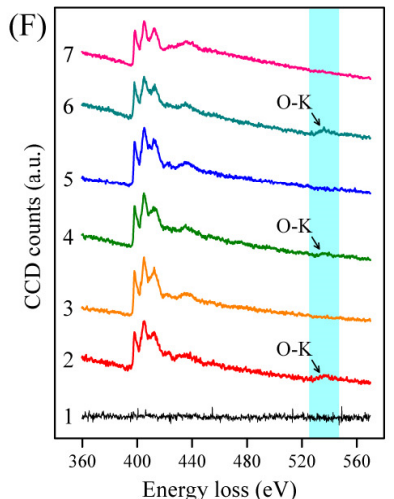

Fig. 3. Aberration-corrected TEM images of pristine $h$-BN (A) and BNOH (D) catalysts along [001] direction; HAADF-STEM images of the pristine $h$-BN (B) and BNOH (E) catalysts; EELS line spectra at 1 to 7 positions of the pristine $h$-BN (C) and BNOH (F) catalysts. 
and functional groups of boron nitride for optimal catalytic performance and to understand its catalytic origin.

To achieve these goals, we made many efforts to explore the functionalization of boron nitride. We adhered to two principles: exposing the edge as much as possible for the reactants' accessibility and maximizing the number of functional groups for abundant active sites. As exemplified in our previous study [30], a sodium-assisted high-temperature steam activation process rendered the best catalytic efficacy of boron nitride in the ODH reaction. A comparison of the aberration-corrected TEM images of boron nitride before and after functionalization in Fig. 3 reveals the generation of a large number of accessible edges after functionalization. Also, lattice relaxations and distortions at the edge of boron nitride were observed. High-sensitivity low-energy ion scattering (HS-LEIS) studies revealed that a gradual substitution of nitrogen by oxygen occured during the functionalization of pristine boron nitride. Furthermore, electron energy loss spectroscopy (EELS, Fig. 3) of boron nitride clearly affirmed that more edges other than those in the planes of boron nitride were functionalized by oxygen atoms. Considering the inert nature of pure boron nitride, these evolutions in structure and composition at the edge of boron nitride after the functionalization are likely to contribute to the unique catalytic function in the ODH reaction of propane.

These insights shed light on the catalytic origin of activated boron nitride in the ODH reaction. Initially, the explicit configuration and functional groups at the edges of active boron nitride were identified using advanced spectroscopy techniques, including K-edge EELS, X-ray photoelectron spectroscopy, two-dimensional multiple-quantum MAS NMR, and infrared spectroscopy. We precisely confirmed the dominantly exposed zig-zag boron-terminated edges and the co-existence of B-O-B and $\mathrm{B}-\mathrm{OH}$ groups at these edges of the active boron nitride catalyst. When only $\mathrm{C}_{3} \mathrm{H}_{8}$ was pulsed into the boron nitride catalyst, there was no propane conversion or generation of any products, indicating that the oxygen-containing edge boron species themselves have no catalytic activity for $\mathrm{C}-\mathrm{H}$ cleavage in propane [30].

A more interesting finding from in situ IR was that the intensity of B-OH groups gradually decreased only with co-feeding of propane and oxygen, accompanied by the formation of propylene, indicating that the - $\mathrm{OH}$ groups interacted with molecular oxygen and were incorporated into the reaction network. Isotope-labeling measurements provided further insight into this process, where the hydrogen atoms in the $\mathrm{B}-\mathrm{OH}$ group were abstracted during the $\mathrm{ODH}$ reaction. The kinetic analysis confirmed that oxygen reaction dependence followed up the L-H model, indicating a dissociative adsorption of molecular oxygen in the reaction process. Meanwhile, ${ }^{180}$ isotope tracer study demonstrated that an oxygen exchange between the surface oxygen atoms in the B-OH group and molecular oxygen occurred in the reaction process [30]. These objective findings allowed us to conclude that the $\mathrm{B}-\mathrm{OH}$ groups at the edge of boron nitride are initially oxidized by molecular oxygen, and trigger the dehydrogenation reaction of propane. Reaction order of propane was two, and the normal KIE $(\mathrm{kH} / \mathrm{kD})$ of 1.4-1.5 was observed, indicating that the activation of propane determined the total reaction rate [30]. Based on the above observations, a relative simple reaction pathway (Scheme 1) is proposed including a redox reaction cycle. The $\mathrm{B}-\mathrm{OH}$ sites initially react with molecular oxygen, leading to the production of B-O-O-B intermediates (oxidation step). The B-O-O-B species further abstract the hydrogen atoms from propane, forming $\mathrm{C}_{3} \mathrm{H}_{6}$ and $\mathrm{H}_{2} \mathrm{O}$ (reduction step), and then recover to B-OH sites with the assistance of water.

Recently, the Su group's operando infrared spectroscopy and 180 isotope tracer study demonstrated that the active sites of $\mathrm{B}-\mathrm{O}(\mathrm{H})$ were formed at the edges of boron nitride via the aid of ethane, and the dehydrogenation cycle could be completed with the assistance of $\mathrm{O}_{2}$ at $\mathrm{B}-\mathrm{O}$ sites [34]. They also pointed out that a detailed comparison between the roles of the $\mathrm{B}-\mathrm{O}$ and $\mathrm{B}-\mathrm{OH}$ groups in the alkane $\mathrm{ODH}$ reaction was still of value for a deep understanding of the reaction mechanism. Another recent paper from Hermans' group reported that boron-containing materials, such as boron carbide, titanium boride, nickel boride, cobalt boride, hafnium boride, tungsten boride, and elemental boron, showed the same exceptional behavior in the propane ODH reaction as boron nitride [39]. Based on the results from X-ray photoelectron and IR spectroscopy, they suggested the formation of an analogous surface-stabilized BOx active site for all tested boride catalysts [39]. These findings support our viewpoints on the catalytic origin of boron nitride in $\mathrm{ODH}$.

\section{Summary and future outlook}

An ODH catalyst, boron nitride, was discovered recently, and features superior selectivity toward light olefins, excellent stability, and atom economy for valuable carbon-based products by minimizing $\mathrm{CO}_{2}$ emission. More specifically, the key points are as follows:

(1) Pure boron nitride is catalytically inert, and an activation period is required under the reaction conditions. Hence, a straightforward strategy for preparing an active boron nitride catalyst with chemical oxy-functionalization at the edges via alkali-metal-assisted steam activation to tailor and functionalize the terminal edge of boron nitride to enhance catalytic efficacy is desired.

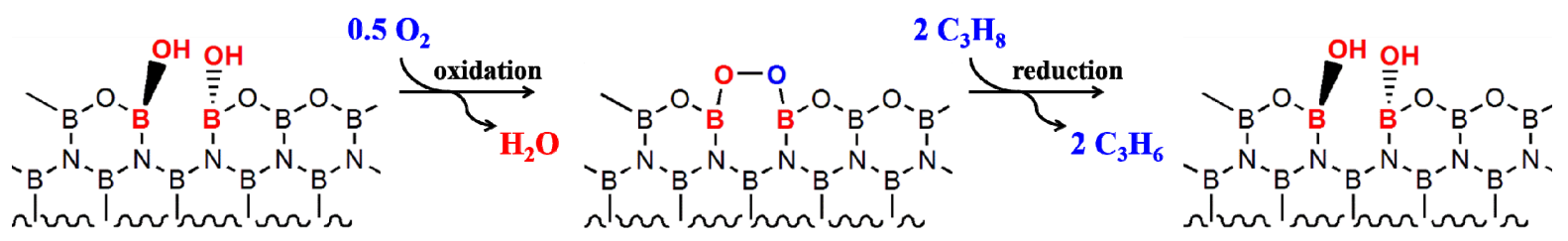

Scheme 1. The proposed redox reaction cycle in the oxidative dehydrogenation of propane over the boron nitride. 
(2) Boron nitride is highly promising for industrial implementation because of its high production of light olefins, negligible formation of $\mathrm{CO}_{2}$, remarkable catalyst stability, superior anti-oxidation ability, and excellent thermal conductivity.

(3) A new redox reaction cycle is proposed, i.e. neighboring B-OH sites are initially oxidized by molecular oxygen (oxidation step), and then trigger dehydrogenation of light alkanes to olefins (reduction step).

The development of this novel catalyst system not only opens up a new research direction in selective cleavage of $\mathrm{C}-\mathrm{H}$ bonds of alkanes by metal-free catalysts, but also enriches our fundamental understanding of the industrially important ODH process. Nevertheless, from the point of view of activity, selectivity, and stability, there is still room for improvement in catalytic performance. It should be pointed out that minimizing the cleavage of $\mathrm{C}-\mathrm{C}$ bonds remains challenging under the oxidative dehydrogenation conditions. Furthermore, for such a novel catalytic system, there is an urgent need to develop new structure-tuning methods for optimizing the catalytic performance, and to clarify the roles of the $\mathrm{B}-\mathrm{O}$ and $\mathrm{B}-\mathrm{OH}$ groups in the alkane ODH reactions. Future studies are expected to involve theoretical simulations and the capture of reaction intermediates to disclose the reaction mechanism under the reaction conditions.

\section{Acknowledgment}

We thank Prof. De Chen (Department of Chemical Engineering, Norwegian University of Science and Technology) and Prof. Xue-Zhi Duan (State Key Laboratory of Chemical Engineering,East China University of Science and Technology) for the valuable discussions.

\section{References}

[1] A. Corma, F. V. Melo, L. Sauvanaud, F. Ortega, Catal. Today, 2005, 107-108, 699-706.

[2] J. Z. Li, Y. X. Wei, J. R. Chen, P. Tian, X. Su, S. T. Xu, Y. Qi, Q. Y. Wang,
Y. Zhou, Y. L. He, Z. M. Liu, J. Am. Chem. Soc., 2012, 134, 836-839.

[3] L. S. Zhong, F. Yu, Y. L. An, Y. H. Zhao, Y. H. Sun, Z. J. Li, T. J. Lin, Y. Z. Lin, X. Z. Qi, Y. Y. Dai, L. Gu, J. S. Hu, S. F. Jin, Q. Shen, H. Wang, Nature, 2016, 538, 84-87.

[4] E. McFarland, Science, 2012, 338, 340-342.

[5] J. J. H. B. Sattler, J. Ruiz-Martinez, E. Santillan-Jimenez, B. M. Weckhuysen, Chem. Rev., 2014, 114, 10613-10653.

[6] https://www.uop.com/processing-solutions/petrochemicals/olef ins/\#propylene.

[7] K. J. Caspary, H. Gehrke, M. Heinritz-Adrian, M. Schwefer, "Dehydrogenation of alkanes" in: Handbook of Heterogeneous Catalysis, G. Ertl, H. Knozinger, F. Schuth, J. Weitkamp, Eds., Wiley-Vch, 2008, Vol. 6, Chap. 14.5.

[8] L. Shi, G. M. Deng, W. C. Li, S. Miao, Q. N. Wang, W. P. Zhang, A. H. Lu, Angew. Chem. Int. Ed., 2015, 54, 13994-13998.

[9] A. S. Bodke, D. A. Olschki, L. D. Schmidt, E. Ranzi, Science, 1999, 285, 712-715.

[10] R. Grabowski, Catal. Rev. Sci. Eng., 2006, 48, 199-268.

[11] C. A. Carrero, R. Schloegl, I. E. Wachs, R. Schomaecker, ACS Catal., 2014, 4, 3357-3380.

[12] F. Cavani, N. Ballarini, A. Cericola, Catal. Today, 2007, 127, 113-131.

[13] C. Carrero, M. Kauer, A. Dinse, T. Wolfram, N. Hamilton, A. Trunschke, R. Schlogl, R. Schomacker, Catal. Sci. Technol., 2014, 4, 786-794.

[14] L. Leveles, K. Seshan, J. A. Lercher, L. Lefferts, J. Catal., 2003, 218, 296-306.

[15] S. Vajda, M. J. Pellin, J. P. Greeley, C. L. Marshall, L. A. Curtiss, G. A. Ballentine, J. W. Elam, S. Catillon-Mucherie, P. C. Redfern, F. Mehmood, P. Zapol, Nat. Mater., 2009, 8, 213-216.

[16] E. V. Kondratenko, O. V. Buyevskaya, M. Baerns, Top. Catal., 2001, $15,175-180$.

[17] Y. M. Liu, W. L. Feng, T. C. Li, H. Y. He, W. L. Dai, W. Huang, Y. Cao, K. N. Fan, J. Catal., 2006, 239, 125-136.

[18] A. A. Lemonidou, L. Nalbandian, I. A. Vasalos, Catal. Today, 2000, $61,333-341$

[19] R. B. Watson, U. S. Ozkan, J. Catal., 2000, 191, 12-29.

[20] Q. H. Zhang, C. J. Cao, T. Xu, M. Sun, J. Z. Zhang, Y. Wang, H. L. Wan, Chem. Commun., 2009, 2376-2378.

[21] B. Farin, P. Eloy, C. Poleunis, M. Devillers, E. M. Gaigneaux, Catal. Sci. Technol., 2016, 6, 6046-6056.

[22] J. H. Li, C. C. Wang, C. J. Huang, W. Z. Weng, H. L. Wan, Catal. Lett,

\section{Graphical Abstract}

Chin. J. Catal., 2018, 39: 908-913 doi: 10.1016/S1872-2067(18)63060-8

\section{A viewpoint on catalytic origin of boron nitride in oxidative dehydrogenation of light alkanes}

Lei Shi, Dongqi Wang, An-Hui Lu*

Dalian University of Technology;

Institute of High Energy Physics, Chinese Academy of Sciences

This viewpoint illustrates that the B-OH groups at the zig-zag edge of boron nitride could be catalytically active in the ODH reaction of light alkanes by analyzing recent progress in the use of boron nitride for the ODH reaction and presenting much new evidence.

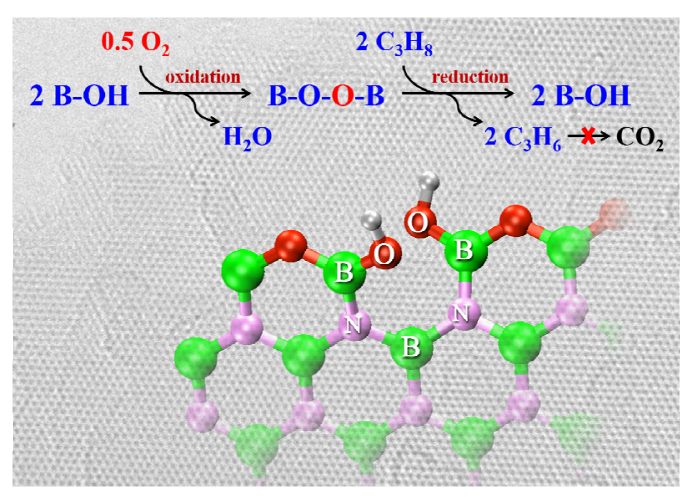


2010, 137, 81-87.

[23] A. Pakdel, Y. Bando, D. Golberg, Chem. Soc. Rev., 2014, 43, 934-959.

[24] Q. H. Weng, X. B. Wang, X. Wang, Y. Bando, D. Golberg, Chem. Soc. Rev., 2016, 45, 3989-4012.

[25] Y. Wang, L. Shi, W. D. Lu, Q. Sun, Z. F. Wang, C. Y. Zhi, A. H. Lu, ChemCatChem, 2017, 9, 1363-1367.

[26] T. W. Hansen, J. B. Wagner, P. L. Hansen, S. Dahl, H. Topsoe, C. J. H. Jacobsen, Science, 2001, 294, 1508-1510.

[27] L. J. Gao, Q. Fu, M. M. Wei, Y. F. Zhu, Q. Liu, E. Crumlin, Z. Liu, X. H. Bao, ACS Catal., 2016, 6, 6814-6822.

[28] Y. H. Zhang, X. F. Weng, H. A. Li, H. B. Li, M. M. Wei, J. P. Xiao, Z. Liu, M. S. Chen, Q. Fu, X. H. Bao, Nano Lett., 2015, 15, 3616-3623.

[29] J. T. Grant, C. A. Carrero, F. Goeltl, J. Venegas, P. Mueller, S. P. Burt, S. E. Specht, W. P. McDermott, A. Chieregato, I. Hermans, Science, 2016, 354, 1570-1573.

[30] L. Shi, D. Q. Wang, W. Song, D. Shao, W. P. Zhang, A. H. Lu, ChemCatChem, 2017, 9, 1788-1793.

[31] C. Trionfetti, I. V. Babich, K. Seshan, L. Lefferts, Appl. Catal. A, 2006, $310,105-113$.
[32] J. M. Venegas, J. T. Grant, W. P. McDermott, S. P. Burt, J. Micka, C. A. Carrero, I. Hermans, ChemCatChem, 2017, 9, 2118-2127.

[33] L. Shi, B. Yan, D. Shao, F. Jiang, D. Q. Wang, A. H. Lu, Chin. J. Catal., 2017, 38, 389-395.

[34] R. Huang, B. S. Zhang, J. Wang, K. H. Wu, W. Shi, Y. J. Zhang, Y. F. Liu, A. M. Zheng, R. Schloegl, D. S. Su, ChemCatChem, 2017, 9, 3293-3297.

[35] F. S. Guo, P. J. Yang, Z. M. Pan, X. N. Gao, Z. K. Xie, X. C. Wang, Angew. Chem. Int. Ed., 2017, 56, 8231-8235.

[36] L. H. Li, J. Cervenka, K. Watanabe, T. Taniguchi, Y. Chen, ACS Nano, 2014, 8, 1457-1462.

[37] K. H. Lee, H. J. Shin, B. Kumar, H. S. Kim, J. Lee, R. Bhatia, S. H. Kim, I. Y. Lee, H. S. Lee, G. H. Kim, J. B. Yoo, J. Y. Choi, S. W. Kim, Angew. Chem. Int. Ed., 2014, 53, 11493-11497.

[38] C. R. Dean, A. F. Young, I. Meric, C. Lee, L. Wang, S. Sorgenfrei, K. Watanabe, T. Taniguchi, P. Kim, K. L. Shepard, J. Hone, Nat. Nanotechnol., 2010, 5, 722-726.

[39] J. T. Grant, W. P. McDermott, J. M. Venegas, S. P. Burt, J. Micka, S. P. Phivilay, C. A. Carrero, I. Hermans, ChemCatChem, 2017, 9, 3623-3626.

\title{
氮化硼催化低碳烷烃氧化脱氢的活性起源探讨
}

\author{
石 䂞 ${ }^{\mathrm{a}}$ ，王东琪 ${ }^{\mathrm{b}}$ ，陆安慧 ${ }^{\mathrm{a},{ }^{*}}$ \\ ${ }^{\mathrm{a}}$ 大连理工大学化工学院精细化工国家重点实验室, 辽宁大连 116024 \\ b 中国科学院高能物理研究所, 北京 100049
}

\begin{abstract}
摘要: 页岩气的急速开采推动了以天然气替代石油的资源革命. 除主组分甲烷外, 天然气、页岩气中还包含大量乙烷、丙 烷等低碳烷烃资源, 将这些储量丰富的碳资源直接转化为烯烃等基础化学品有望革新以原油为基础的化学工业. 现有烷 烃催化脱氢制烯烃工艺中, 直接脱氢过程吸热、热力学受限, 且存在催化剂迅速失活的难题; 而氧化脱氢是放热过程、无 平衡限制, 也无积碳等引发催化剂失活的问题, 有利于提高反应效率、降低能耗, 代表了更为高效和经济的新路线. 但作为 一个热力学爬坡过程, 目前金属氧化物催化剂上烯烃产物很容易深度氧化到 $\mathrm{CO}_{2}$, 选择性仍有待提高. 非金属氮化硼能够 有效活化低碳烷烃中的 C-H 键, 促进烷烃氧化脱氢, 并能够有效抑制深度氧化产物的生成, 解决低碳烷烃临氧脱氢过程中 产物易深度氧化的固有难题. 本文综述了近期氮化硼在乙烷、丙烷、丁烷等低碳烷烃氧化脱氢制烯烃反应中的研究进展. 以丙烷氧化脱氢为例, 通过比较文献报道的几种氮化硼材料的氧化脱氢性能, 发现差基化氮化嗍显示了最高的烯烃选择性 和时空收率, 以 $20.6 \%$ 的丙烷转化率为基准, 烯烃选择性超过 $90 \%$, 而时空收率可达 $6.8 \mathrm{~g}_{\text {olefin }} \mathrm{g}_{\text {cat }}{ }^{-1} \mathrm{~h}^{-1}$. 在此基础上, 本文重 点讨论了对于氮化硼材料催化活性起源的认识. 主要实验事实和结论包括: 氮化硼自身几乎没有氧化脱氢活性, 而在烷烃 氧化脱氢反应条件下存在活性诱导期; 活性诱导期伴随着氮化硼边沿氧官能团化过程; 氮化嗍边沿 B-O 官能团没有脱氢 活性, 而 B-OH 官能团参与了氧化脱氢过程, 辅助分子氧引发低碳烷烃脱氢反应; 分子氧在羟基氮化硼边沿解离活化, 反应 过程中与边沿结构氧存在动态交换; 氮化硼边沿羟基化定向合成过程可显著增强氧化脱氢反应活性. 氮化硼作为一类新 型烷烃氧化脱氢催化剂, 目前正处于研究的初始阶段. 因此, 本文最后总结了一些关于氮化硼烷烃脱氢催化体系仍需深入 研究的科学问题.
\end{abstract}

关键词: 氮化硼; zig-zag边; 硼羟基; 低碳烷烃; 氧化脱氢; 诱导期

收稿日期: 2018-01-26. 接受日期: 2018-02-22. 出版日期: 2018-05-05.

*通讯联系人. 电话/传真: (0411)84986112; 电子信箱: anhuilu@dlut.edu.cn

基金来源：国家自然科学基金重点项目(21733002); 国家自然科学基金 (U1462120, 21403027); 长江学者奖励计划(T2015036)

本文的电子版全文由Elsevier出版社在ScienceDirect上出版(http://www.sciencedirect.com/science/journal/18722067). 